\title{
Analysis and Design of Damping Circuit Parameters for LCC Valves Based on Broadband Model
}

\author{
Yingjie Tang, Zheren Zhang * and Zheng $\mathrm{Xu}$ (1) \\ College of Electrical Engineering, Zhejiang University, Hangzhou 310027, China; 11810049@zju.edu.cn (Y.T.); \\ xuzheng007@zju.edu.cn (Z.X.) \\ * Correspondence: 3071001296zhang@zju.edu.cn; Tel.: +86-0571-8795-2074
}

Received: 22 January 2020; Accepted: 25 February 2020; Published: 28 February 2020

\begin{abstract}
Damping circuits are installed inside the converter valve to limit commutation overshoots. They have significant effects on the valve's turn-off performances, which should be carefully considered in parameter design. First, the calculation models for the turn-off process are discussed, including the conventional low frequency model and the broadband model. Then, it is found that high-frequency equipment parameters have significant effects on the transient valve voltage, which means that the conventional analytical methods based on low-frequency models is not suitable for damping circuit parameter design. The relationships between the turn-off performances and damping circuit parameters have also been analyzed in detail with the broadband model. To achieve better economic efficiency, this paper proposes a novel method for damping circuit parameter optimization, which combines the electromagnetic transient (EMT) calculation and the numerical optimization. Last, the case study is carried out based on a practical $\pm 1100 \mathrm{kV}$ ultra-high-voltage direct-current (UHVDC) transmission project, which proves the reliability and flexibility of the proposed method.
\end{abstract}

Keywords: converter valve; damping circuit; broadband model; parameter optimization

\section{Introduction}

The converter valve is the core equipment of high-voltage direct-current (HVDC) transmission projects. It should be carefully designed to reduce the impact of various possible disturbances during its continuous operation [1-4]. Limited by the voltage and current capabilities of switching devices, most ultra HVDC (UHVDC) transmission projects adopt line-commutated converters (LCCs) that are composed of series thyristors for $\mathrm{AC} / \mathrm{DC}$ transformation. To limit the commutation overshoot arising from the turn-off of thyristor valve, a damping circuit is connected to each thyristor in parallel [5]. The parameter design of damping circuit is always an important and practical issue in the converter valve design, which is also the main concern of this article.

Previous literatures have tried to derive a complete analytical model for the turn-off process of converter valve [6-9], and most of them are focused on how to establish an applicable turn-off model of thyristor [10-16]. Reference [10] proposed a complex physical model based on fundamental semiconductor equations that are too complicated for circuit analysis. References [11-13] regarded the thyristor as time-variable resistance, while references [14-16] represented the thyristor as dynamic current source. If the resistance model was used, the impedance matrix should be rebuilt once the thyristor state changes. In contrast, only the vector of injection current need to be modified in the current model, which is convenient and widely applied in practical engineering. A common point of the above studies is that the high frequency characteristics of valve equipment are neglected for simplification. However, the effects of high frequency parameters on valve turn-off process should be further analyzed, due to the broadband nature of commutation overshoot [17]. 
For valve arrester selections and insulation co-ordination studies, the peak value of continuous operating voltage (PCOV), including commutation overshoots, is an important factor to be considered. Meanwhile, other converter valve turn-off performances, such as power losses and valve voltage rise rate, are also related to damping circuit design. References $[8,18]$ adopted the method of 'trial and error' in their designs, based on the analytical relationships between the damping circuit parameters and the turn-off performances. For convenience, reference [19] summarized specific diagrams to easily choose suitable RC values at given overshoot coefficient. Low-frequency equivalent circuits are used in the above references, since the analytical method may not fit for more complicated circuit models. However, a broadband model is considered more accurate to evaluate the turn-off performances [17], with the numerical calculation method introduced instead of the analytical method. References $[20,21]$ applied the electromagnetic transient (EMT) program for performance evaluations and established a design procedure aimed at the lowest capacitance, which is one-sided. Reference [22] suggested that a satisfactory optimization for the nonlinear electrical system design would be obtained if the EMT programs and optimization algorithms are combined. Mathematically, the converter valve damping circuit parameter design can be considered as a constrained multi-variable multi-objective optimization problem with no derivatives available. To the authors' knowledge, no literature has discussed the application of numerical method-based optimization approach to damping circuit parameter design, which is just the focus of our article.

With the goal of finding an appropriate design method for damping circuits of thyristor valve, this paper combines the EMT calculation and the numerical optimization method to optimize the damping resistance and the damping capacitance. The main contributions of this paper are presented as follows: (1) A comparative analysis has been conducted to demonstrate the effects of high frequency parameters on the turn-off process; the results show that a broadband model is necessary for an accurate description of the turn-off performances, which is the basis for the damping circuit design. (2) A novel optimization method for damping circuit parameters has been proposed; this method is derivative-free and particularly fit for the cases where broadband models and unbalanced voltage distribution are considered; the validity and flexibility of the proposed optimization approach are verified and discussed. Compared to the traditional analytical method, the proposed method is more reliable and flexible.

The rest of this paper is organized as follows. Calculation models for the turn-off process are established in Section 2. The effects of high frequency parameters on the transient valve voltage are elaborated. Relationships between the turn-off performances and the damping circuit parameters are analyzed in Section 3. Section 4 gives a comprehensive introduction of the background and scheme of the proposed optimization method. The reliability and flexibility of this method are discussed by case studies presented in Section 5. Finally, conclusions are summarized in Section 6.

\section{Calculation Models of The Turn-off Process}

As can be seen in Figure 1, the HVDC transmission project is a complex system composed of various equipment. Electrical power generated in the sending end power grid are transferred from the rectifier station to the inverter station through DC transmission lines, finally feeding into the receiving end power grid.

\subsection{The Conventional Low Frequency Model}

Theoretically, the commutation overshoots produced in the converter at one side may be coupled to the converter at the other side through DC links. However, considering the low-pass characteristic of the power transmission channel, including smoothing reactors and DC filters, the above transient voltages that act as high-frequency disturbances has been attenuated to nearly zero when arriving at the other side.

In UHVDC projects, two 12-pulse bridges are series connected to make up one pole of the converter station. The firing pulses sent to the 12-pulse bridges are simultaneous, while a phase difference of $30^{\circ}$ between the two 6-pulse bridges inside is expected [9]. The effect of electrical couplings between 
the two 6-pulse bridges, except for the induced voltages and currents, is determined by the size of common impedance $Z_{c}$ at the point of common coupling (PCC). In modern converter stations there are enough reactive power compensation equipment put into service for the voltage stability, resulting in a small $Z_{\mathrm{c}}$. Generally, the effects of turn-off process in one 6-pulse bridge on the valve voltage stress of other 6-pulse bridges are negligible.

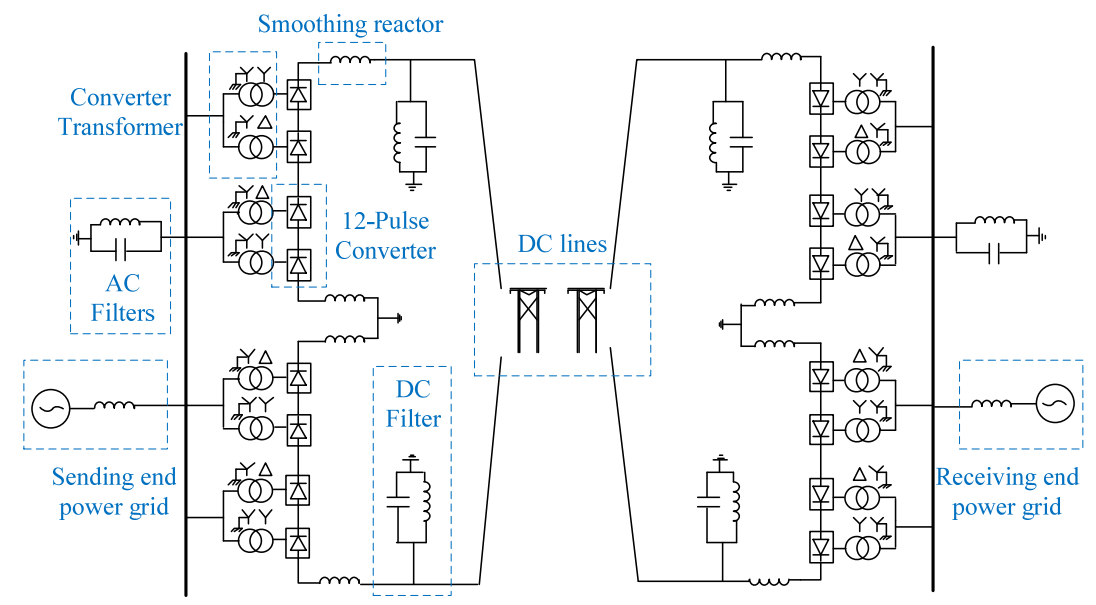

Figure 1. Basic Topology of UHVDC Transmission Project.

Thus, only a 6-pulse bridge needs to be considered for commutation overshoot calculation. Figure $2 \mathrm{a}$ depicts the working circuit when $\mathrm{V}_{1}$ just commutates to $\mathrm{V}_{3}$ and is going to be turned off. $e_{\mathrm{a}}, e_{\mathrm{b}}$, and $e_{\mathrm{c}}$ are the three phase voltages in the valve side windings. $L_{\mathrm{t}}$ is the leakage reactance of converter transformer. $R_{\mathrm{d}}$ and $C_{\mathrm{d}}$ represent the integration of damping circuits. The DC side output of the 6-pulse bridge is the direct current $I_{\mathrm{d}}$ with negligible harmonics due to a large smoothing reactance $L_{\mathrm{d}}$. As thyristors in blocking valves $\left(\mathrm{V}_{4}, \mathrm{~V}_{5}\right.$, and $\left.\mathrm{V}_{6}\right)$ are considered as open circuits while those in conducting valves $\left(\mathrm{V}_{2}\right.$ and $\left.\mathrm{V}_{3}\right)$ are considered as short circuits, an equivalent circuit of compact form is established in Figure $2 \mathrm{~b}$. Series connected thyristors in the outgoing valve are represented by an integrated current source $i_{\mathrm{r}}(t)$, for which the thyristor turn-off model in exponential form is adopted. The method proposed in [23] is used for parameter extraction. Moreover, a simplified circuit can be derived under the assumption that the transformer phase not included in the commutation process (phase c here) carries negligible current and has no effect on the turn off process [24], as shown in Figure 2c. The above calculation circuits are referred to as the conventional model and it features the utilization of low-frequency equipment models.

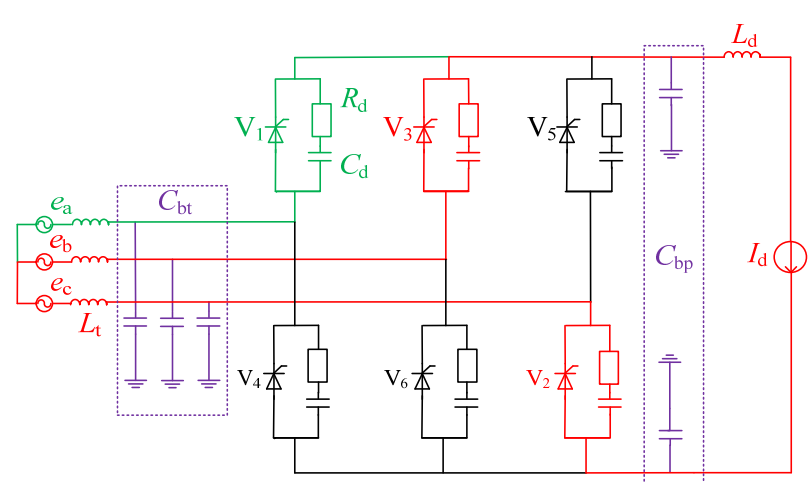

(a) Working circuit

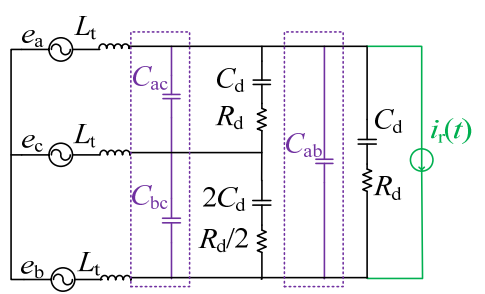

(b) Equivalent circuit

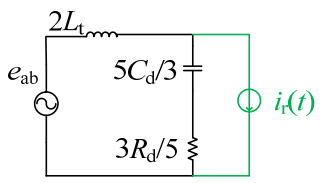

(c) Simplified circuit

Figure 2. Conventional Model for Turn-off Process. 
Analytical expressions for the turn-off performances can be derived based on the conventional model [21]. However, the effect of oversimplified equipment models on accuracy should been further analyzed.

\subsection{The Broadband Model}

Considering the broadband nature of commutation overshoot (mainly distributes from tens to hundreds $\mathrm{kHz}$ ), more accurate models of valve equipment applicable over a broad frequency range should be established. The concept and modeling method of the broad model have been elaborated in [25-27]. Here, we introduce several broadband models of valve equipment.

\subsubsection{Converter Transformer}

Limited by transportation ability, converter transformers used in UHVDC projects are assembled onsite by three single-phase converter transformers. Figure 3a shows the broadband model of single-phase converter transformer [28]. $R_{\mathrm{tm}}$ and $L_{\mathrm{tm}}$ denote the core loss resistance and the magnetization inductance; $R_{\mathrm{t} 1}, L_{\mathrm{t} 1}$, and $R_{\mathrm{t} 2}, L_{\mathrm{t} 2}$ represent the resistances and the inductances of the primary winding and the secondary winding, respectively. High frequency parameters include: $C_{\mathrm{t} 1}$ and $C_{\mathrm{t} 2}$ are parasitic capacitances inside the transformer windings; $C_{\mathrm{t} 1 \mathrm{~g}}$ and $C_{\mathrm{t} 2 \mathrm{~g}}$ are stray capacitances between the transformer windings and ground; $C_{\mathrm{t} 12}$ is the stray capacitance between the primary winding and the secondary winding. Besides, the stray inductances $L_{\text {ts }}$ of transformer windings are included in $L_{\mathrm{t} 1}$ and $L_{\mathrm{t} 2}$. Model parameters could be obtained from filed tests [29].

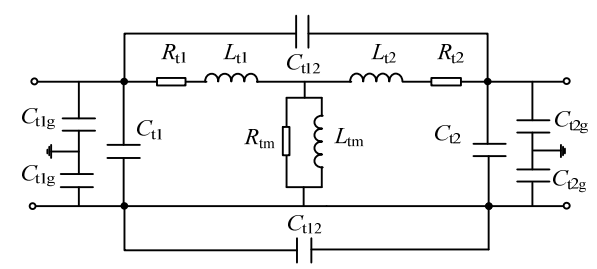

(a) The broad model of converter transformer

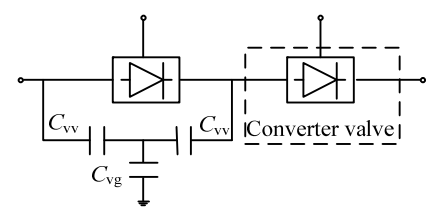

(c) The external model of converter valve

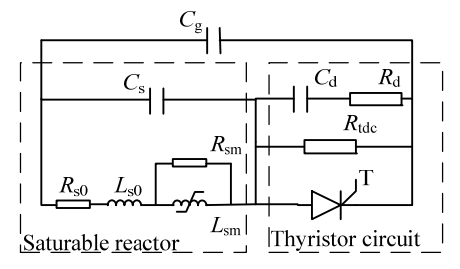

(b) The internal model of converter valve

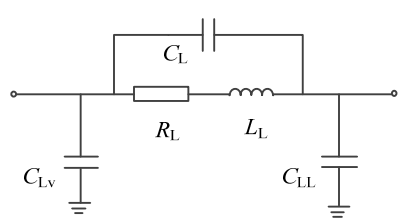

(d) The broadband model of smoothing reactor

Figure 3. The Broadband Models of Valve Equipment.

\subsubsection{Wall Bushing}

$\mathrm{AC}$ and DC switchyards are connected to the valve hall through wall bushings for mechanical support and electrical insulation. The electrical coupling effect between the wall bushing and surroundings is usually represented by a stray capacitance to ground at the level of $\mathrm{pF}$, as shown in Figure 2a. $C_{\mathrm{bt}}$ and $C_{\mathrm{bp}}$ are placed at the valve side windings and pole lines, according to practical arrangements. $C_{\mathrm{ab}}, C_{\mathrm{ac}}$ and $C_{\mathrm{bc}}$ in Figure $2 \mathrm{~b}$ are obtained from the Y- $\Delta$ transformation of $C_{\mathrm{bt}}$ and $C_{\mathrm{bp}}$. The values of stray capacitances are related with applied voltage levels and can be acquired from the product data sheets.

\subsubsection{Converter Valve}

The hierarchy of the broadband model of converter valve [30] are clearly illustrated in Figure 3, including the internal model in Figure $3 \mathrm{~b}$ and the external model in Figure 3c. The internal model consists of the saturable reactor, the thyristor with auxiliary circuits and the grading capacitance $C_{\mathrm{g}}$. In the saturable reactor, the resistance and the air core inductance of the primary winding are denoted 
as $R_{\mathrm{s} 0}$ and $L_{\mathrm{s} 0}$; the core loss resistance and the magnetizing inductance are denoted as $R_{\mathrm{sm}}$ and $L_{\mathrm{sm}}$; the stray capacitance inside the primary winding is denoted as $C_{\mathrm{s}}$. DC grading resistance $R_{\mathrm{tdc}}$, damping resistance $R_{\mathrm{d}}$ and damping capacitance $C_{\mathrm{d}}$ are connected to the thyristor $\mathrm{T}$ in parallel. Noted that the valve model shown in Figure $3 \mathrm{~b}$ is an integration of multiple series-connected valve modules, with the assumption that all these modules have the same characteristics.

The external model adopts a simple but representative method to describe the capacitive couplings inside and outside the converter valve, as shown in Figure 3c. The stray capacitance between the converter valve and surroundings is denoted as $C_{\mathrm{vg}}$. The coupling effects between components inside the converter valve are represented by the stray capacitances $C_{\mathrm{vv}}$. Parameters of stray capacitances can be obtained by filed measurements or electromagnetic field calculations [29].

\subsubsection{Smoothing Reactor}

Figure $3 \mathrm{~d}$ depicts the broadband model of the smoothing reactor. The main circuit includes the inductance $L_{\mathrm{S}}$ and resistance $R_{\mathrm{S}}$ of the primary winding. The high frequency characteristics are represented by three stray capacitances: the parasitic capacitance across the primary winding $C_{\mathrm{L}}$, the stray capacitance to ground at valve side $C_{\mathrm{Lv}}$ and stray capacitance to ground at the line side $C_{\mathrm{LL}}$. These parameters could also be acquired from product data sheets.

\subsection{Comparative Analysis}

A comparative analysis between the conventional model and the broadband model has been conducted with reference to a practical $\pm 1100 \mathrm{kV}$ UHVDC transmission project in China [31]. PSCAD/EMTDC is chosen as the EMT program for circuit simulation. Model parameters, as presented in Appendix A Table A1, are all practical data, since there is no sense in determining them artificially. The effects of high frequency parameters, mainly stray capacitances, on the turn-off process can be observed from the differences between the transient valve voltage waveforms derived from these two models. To highlight the dependent influence of each high frequency parameter, the others are neglected when one parameter is considered.

\subsubsection{High Frequency Parameters in Converter Transformer}

As shown in Figure 4a, the stray capacitances $C_{\mathrm{t} 1}, C_{\mathrm{t} 1 \mathrm{~g}}$, and $C_{\mathrm{t} 2 \mathrm{~g}}$ have little effect on the transient voltage. The phase shift observed is introduced by the stray inductances $L_{\mathrm{ts}}$. A small phase shift may cause an obvious change of the valve voltage jump, which affects the amplitude of commutation overshoot. However, it can be compensated by modifying the values of $L_{\mathrm{t} 1}$ and $L_{\mathrm{t} 2}$, which is not the focus of our study.

As shown in Figure $4 \mathrm{~b}, \mathrm{c}$, obvious voltage oscillations are imposed on the transient voltage derived from the conventional model when $C_{12}$ and $C_{22}$ are introduced. The valve voltage stresses are significantly affected by these voltage oscillations, which should be carefully considered in the damping circuit design.

\subsubsection{High Frequency Parameters in Wall Bushings}

As plotted in Figure $4 \mathrm{~d}$,e, the effect of $C_{\mathrm{bp}}$ on the transient voltage is negligible, while obvious high frequency voltage components arise with the introduction of $C_{b t}$. Considering that these two stray capacitances are placed at the AC side and DC side of the 6-pulse bridge separately, it indicates that the electrical coupling effect cannot be effectively transferred to other 6-pulse bridges through DC links.

\subsubsection{High Frequency Parameters in Converter valves}

Figure $4 \mathrm{f}$, g illustrate the effect of converter valve high frequency parameters on the turn-off process. It is noted from Figure $4 \mathrm{f}$ that $C_{\mathrm{vv}}$ has little influence on the valve transient voltage. Though no obvious waveform change is observed, the magnitudes of voltage peaks have changed after the 
introduction of $C_{\mathrm{vg}}$, as shown in Figure $4 \mathrm{~g}$. Since the main function of damping circuit is to limit commutation overshoots, it is necessary to consider the effects of $C_{\mathrm{vg}}$ when design the damping circuit.

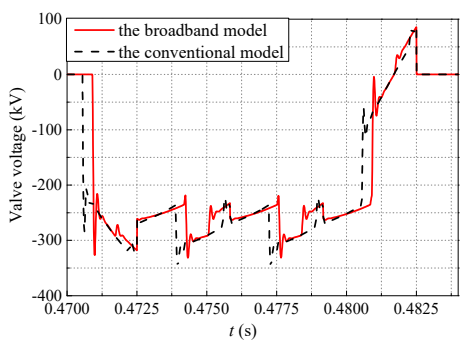

(a) Considering $C_{\mathrm{t} 1}, C_{\mathrm{tg}}$ and $C_{\mathrm{t} 2 \mathrm{~g}}$

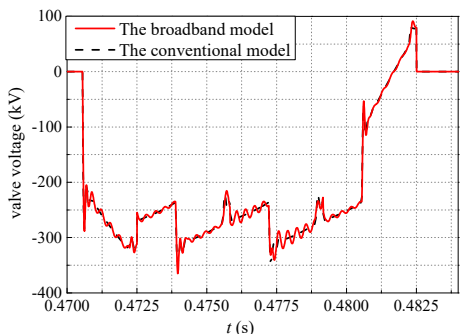

(d) Considering $C_{\mathrm{bt}}$

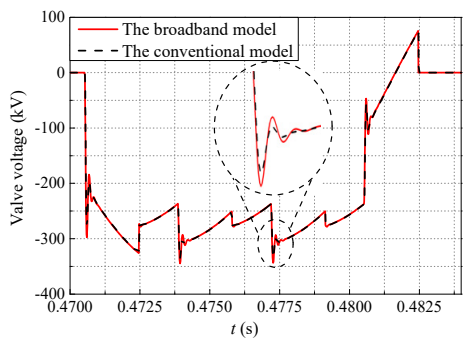

(g) Considering $C_{\text {vg }}$

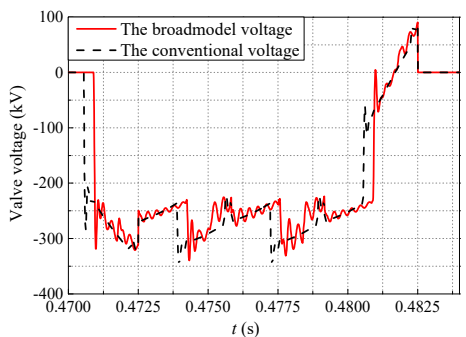

(b) Considering $C_{\mathrm{t} 12}$

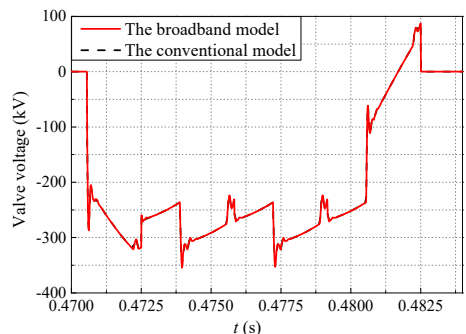

(e) Considering $C_{\mathrm{bp}}$

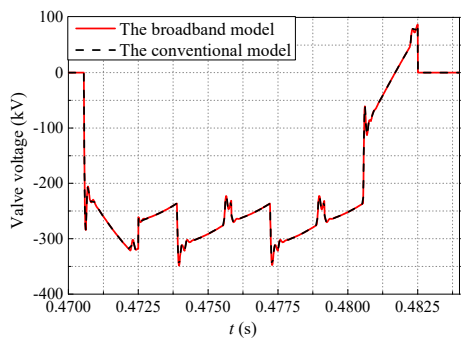

(h) Considering $C_{\mathrm{L}}$

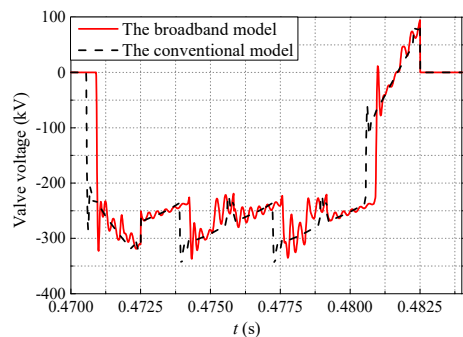

(c) Considering $C_{12}$

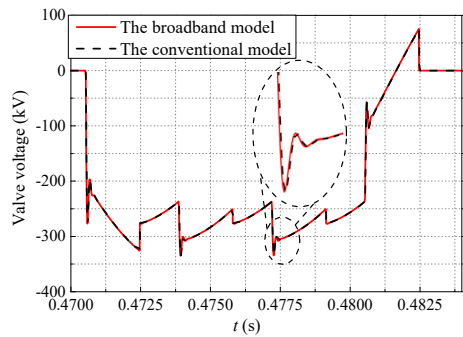

(f) Considering $C_{\mathrm{vv}}$

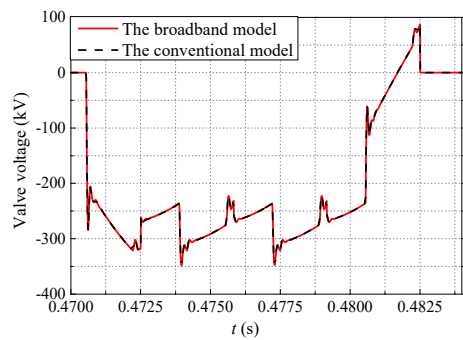

(i) Considering $C_{\mathrm{Lv}}$ and $C_{\mathrm{LL}}$

Figure 4. Comparisons of Transient Valve Voltages Obtained from Two Different Models.

\subsubsection{High Frequency Parameters in Smoothing reactor}

As plotted in Figure 4h,i, the high frequency characteristics of the smoothing reactor has no effect on the transient valve voltage. Again, it proves that DC links are not the transmission paths for electrical couplings between 6-pulse bridges.

\subsection{Summary}

It could be concluded from the above results that high frequency characteristics of valve equipment should be considered for an accurate description of the turn-off process. In practical engineering, even a change of $0.01 \mathrm{pu}$ in PCOV evaluation has nonnegligible economic and engineering significances. It is reasonable and necessary to apply the broadband model into the analysis of issues related to the turn-off process of converter valve. Thus, the broadband model is used in the following sections for the performance analysis and the damping circuit parameter design.

\section{Performance Indicators of Damping Circuit}

The main purpose of installing damping circuits is to limit commutation overshoots. In addition, some other electrical quantities, such as the valve voltage rise rate and the turn-off power loss, should also be considered for a synthetic design of the damping circuit. This section quantifies the turn-off performances of converter valve by three specific parameters, which make up the basis of the damping 
circuit design. These characteristic curves shown in this section are derived from the broadband model of the $\pm 1100 \mathrm{kV}$ UHVDC project with parameters referred to Appendix A. For simplification, the values of voltage and power used below are per-unit values without special notations. The base voltage is selected as the magnitude of converter transformer valve side voltage $E_{\mathrm{v}}$. The base power is selected as the rated DC transmission power $P_{\mathrm{n}}$.

\subsection{Commutation overshoot $U_{\text {ovst }}$}

When the outgoing valve is turned off, voltages across no-conducting valves will experience a rapid change, usually accompanied with oscillations and overshoots. The amplitude of commutation overshoot is mainly determined by three factors: the operating condition, the thyristor reverse recovery characteristics and the damping circuits. The information about the thyristor reverse recovery characteristics are specified in the product data sheets. Given that the delay angle $\alpha$ in the rectifier (or the extinction angle $\gamma$ in the inverter) and the transmission power $P_{\mathrm{d}}$ are set at $17.5^{\circ}$ and $1.1 \mathrm{pu}$, the voltages of nonconducting valves $\left(\mathrm{V}_{1}, \mathrm{~V}_{4}, \mathrm{~V}_{5}\right.$, and $\left.\mathrm{V}_{6}\right)$ during the turn-off process of $\mathrm{V}_{1}$ are presented in Figure $5 a, b$. Subscripts refer to valve numbers. $V_{5}$ and $V_{6}$ are connected in parallel and the transient voltage across them are denoted by $u_{\mathrm{v} 56}(\mathrm{t})$. It is noticed that commutation overshoots produced in the rectifier are higher than those in the inverter. This is because the amplitude of the voltage jump at turn-off in the rectifier is normally larger than that in the inverter. That is why the rectifier model should be selected for PCOV calculation.

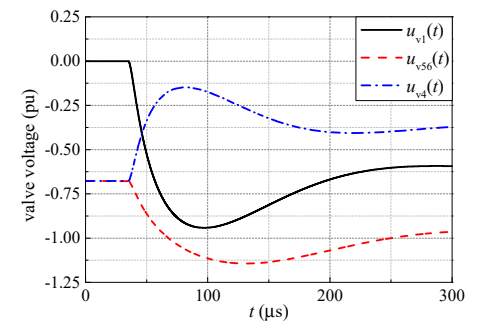

(a) Transient valve voltage in the rectifier

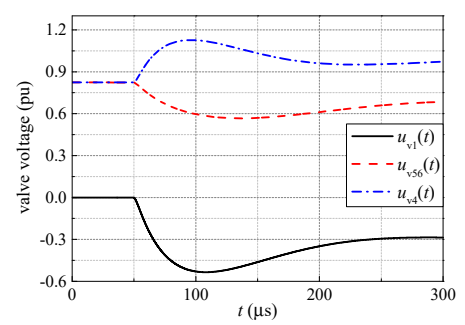

(b) Transient valve voltage in the inverter

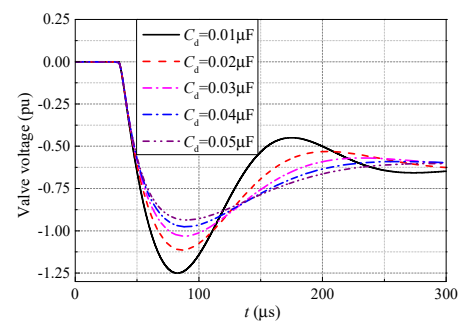

(c) $u_{\mathrm{v} 1}(t)$ under different $C_{\mathrm{d}}$

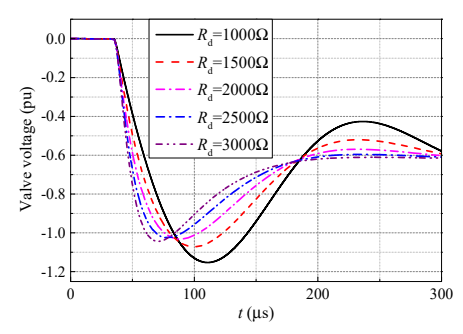

(d) $u_{\mathrm{vl}}(t)$ under different $R_{\mathrm{d}}$

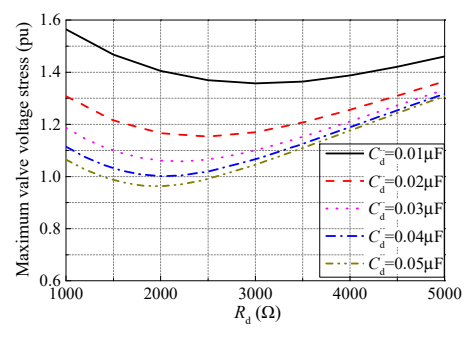

(e) PCOV under different $R_{\mathrm{d}}$ and $C_{\mathrm{d}}$

Figure 5. Characteristics of Commutation Overshoot.

PCOV refers to the maximum repetitive stresses at thyristor valves, while another similar definition, $\mathrm{CCOV}$, refers to the crest value of continuous operating voltage excluding commutation overshoots [32]. The ratio of PCOV to CCOV is defined as $k_{\text {ovst }}$. In practical engineering, $k_{\text {ovst }}$ is usually designated a conservative value empirically based on the project voltage level. For example, the recommended $k_{\text {ovst }}$ in the $1100 \mathrm{kV}$ project is 1.17 [17]. In this way, the safe operation of converter valve is guaranteed while the insulation level of related equipment is increased.

Figure $5 c, d$ show the transient valve voltage waveforms corresponding to different damping circuit parameters. It is found that the amplitude of commutation overshoot decreases as $C_{d}$ increases, while the variation of $C_{\mathrm{d}}$ has little effect on the voltage oscillation frequency. On the contrary, a larger $R_{\mathrm{d}}$ usually indicates an earlier peak time and a faster attenuation of the transient valve voltage. 
Besides, there is always an optimal resistance of the damping resistor corresponding to the minimum commutation overshoot at a given damping capacitance, as can be seen from Figure 5e.

\subsection{Forward Voltage Rise Rate $d u / d t$}

When the thyristor is just turned off, its ability to withstand a high forward voltage rise rate has not restored. Even if the thyristor is staying at the blocking state, it may also be damaged due to ungated turn-on resulted from capacitive displacement current, when a forward voltage with high rise rate is suddenly applied [5]. For safe operation, the maximum forward voltage rise rate $\mathrm{d} u / \mathrm{d} t_{\max }$ should be limited under a specified critical value that is denoted as $\mathrm{d} u / \mathrm{d} t_{\text {lim }}$.

Figure $6 \mathrm{a}, \mathrm{b}$ depict the valve voltage rise rates $\mathrm{d} u / \mathrm{d} t$ at $\mathrm{V}_{1}$ turn-off. Subscripts refer to valve numbers. As can be seen, the valve voltage rise rates reach to their peaks quickly and then decrease fast to be harmless. It should be noted that although the absolute value of the voltage change rate of the outgoing valve is larger than those in blocking valves, only the positive peak of $\mathrm{d} u / \mathrm{d} t_{\mathrm{v} 4}$ is really threatening. Moreover, the valve voltage rise rates in rectifier mode are obviously larger than that in the inverter mode, which indicates that an acceptable design for the rectifier is also suitable for the inverter.

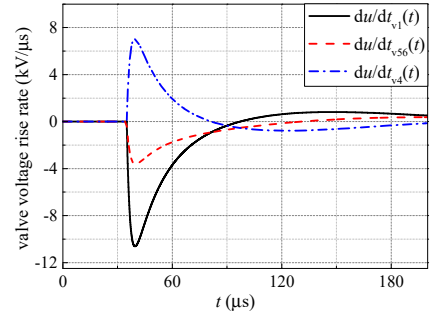

(a) Valve voltage rise rate in the rectifier

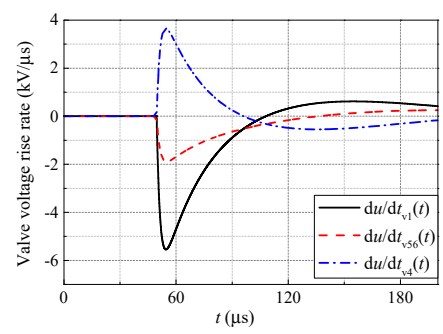

(b) Valve voltage rise rate in the inverter

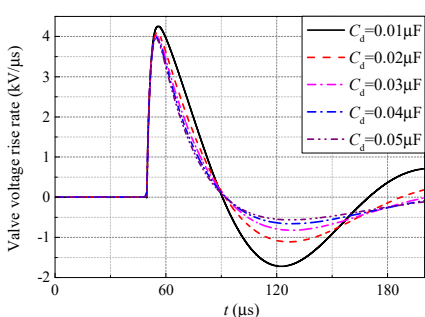

(c) $\mathrm{d} u / \mathrm{d} t$ under different $C_{\mathrm{d}}$

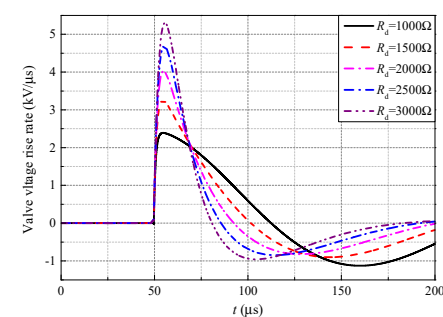

(d) $\mathrm{d} u / \mathrm{d} t$ under different $R_{\mathrm{d}}$

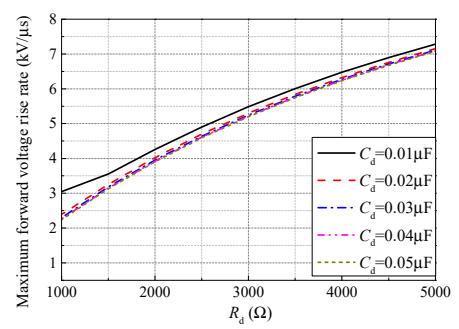

(e) $\mathrm{d} u / \mathrm{d} t_{\text {max }}$ under different $R_{\mathrm{d}}$ and $C_{\mathrm{d}}$

Figure 6. Characteristics of Forward Valve Voltage Rise Rate.

Figure $6 c$,d give the curves of valve voltage rise rates calculated during the turn-off process. It is found that increasing $C_{\mathrm{d}}$ could only slightly reduce the maximum valve voltage rise rate, which is significantly affected by the variation of $R_{\mathrm{d}}$. Specifically, a strong positive correlationship between $\mathrm{d} u / \mathrm{d} t_{\max }$ and $R_{\mathrm{d}}$ is illustrated in Figure 6e.

\subsection{Turn-off Power Losses $P_{L}$}

During the valve turn-off process, the energy stored in the main circuit inductances feeds into the damping circuits to charge the damping capacitances, causing extra power losses on the damping resistance. Besides, the stored charges in the thyristors turned off are dissipated by reverse recovery currents [33], also resulting in power losses on both thyristors and damping resistances. According to practical engineering, $15 \%$ to $30 \%$ of the total power losses in the converter valve are the switching losses [34], which is necessary for the efficiency analysis. The capacity and investment costs of cooling equipment installed inside the converter valve are also affected by the switching loss [35]. Thus, it is necessary to minimize the turn-off power losses $P_{\mathrm{L}}$ as much as possible. 
The cumulative curves of turn-off power losses in different locations are shown in Figure 7a. $P_{\text {L1d }}$ and $P_{\mathrm{L1t}}$ represent the power losses on damping resistances and thyristors inside the outgoing valve; $P_{\text {L456 }}$ represents the power losses at other blocking valves. As can be seen, most of the turn-off power losses are consumed by damping resistances. So, it is reasonable to take the turn-off power losses into account for the damping circuit design.

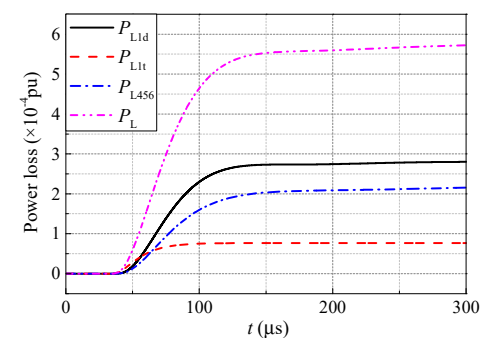

(a) Distribution of turn-off power loss

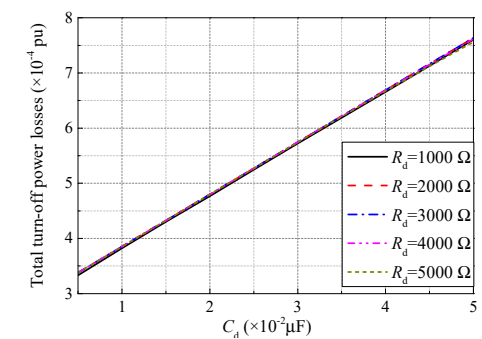

(b) Power losses under different $R_{\mathrm{d}}$ and $C_{\mathrm{d}}$

Figure 7. Characteristics of Turn-off Power Losses.

Figure $7 \mathrm{~b}$ summarizes the total power losses during the turn-off process with respect to different damping circuit parameters. It can be easily found that there is a strong linear relationship between $P_{\mathrm{L}}$ and $C_{\mathrm{d}}$ while the effect of damping resistance on power losses are negligible, although the most energy losses are consumed by damping resistors.

\subsection{Unbalanced Voltage Distribution in Converter Valve}

In general engineering applications, the whole converter valve is equivalent to a single thyristor circuit. In fact, hundreds of thyristors are series connected in one valve for safe operation under high voltage circumstances. Due to manufacturing tolerances, each thyristor may have different reverse recovery characteristics, such as reverse recovery charge $Q_{\mathrm{rr}}$ and reverse recovery time $t_{\mathrm{rr}}$, and thus experiences a different recovery process. $t_{\mathrm{rr}}$ is critical for inversion scheme since an improper $t_{\mathrm{rr}}$ may cause commutation failures. However, this potential threat is largely dependent on the operating condition of converter, not on the damping circuit. The dispersity of reverse recovery charge $Q_{\mathrm{rr}}$ is thought to be a decisive factor for the uneven distribution of thyristor overvoltage during valve turn-off process [6]. According to the $\pm 1100 \mathrm{kV} \mathrm{HVDC}$ project referred to in this article, a converter valve consists of 60 thyristors with an average reverse recovery charge at $3900 \mu \mathrm{C}$. Factory tests on samples show that the distribution range of $Q_{\mathrm{rr}}$ will not exceed $\pm 5 \%$. Obviously, thyristor voltages considering the reverse recovery charge differences cannot be expressed in analytical form.

According to the general law, the distribution of $Q_{\mathrm{rr}}$ in series-connected thyristors usually follow the probability characteristic of the random Gauss distribution. For convenient illustration, the equidistant distribution model is artificially set to demonstrate the dispersion of thyristor voltage. Figure 8 a depicts the thyristor voltage distribution by three transient voltage waveforms corresponding to thyristors with different reverse recovery charges. As can be seen, the thyristor with a smaller $Q_{\text {rr }}$ will withstand a larger reverse voltage peak. It should also be noted that the forward voltage rise rates of thyristors are slightly different from the valve voltage rise rate due to unbalanced voltage distribution.

Figure $8 \mathbf{b}, \mathbf{c}$ give the thyristor voltage stress under different damping circuit parameters, where the distribution range of $Q_{\mathrm{rr}}$ is set as $\pm 10 \%$ for better illustration. An inverse proportional relation between the damping capacitance $C_{\mathrm{d}}$ and the maximum thyristor voltage stresses can be easily observed. The relationship between the damping resistance $R_{\mathrm{d}}$ and the maximum thyristor voltage stress is similar to the quadratic relation of commutation overshoot to $R_{\mathrm{d}}$. Calculation results shows that the differences between thyristor reverse recovery charges have a smaller effect on voltage stresses at valve level and the turn-off power losses. 

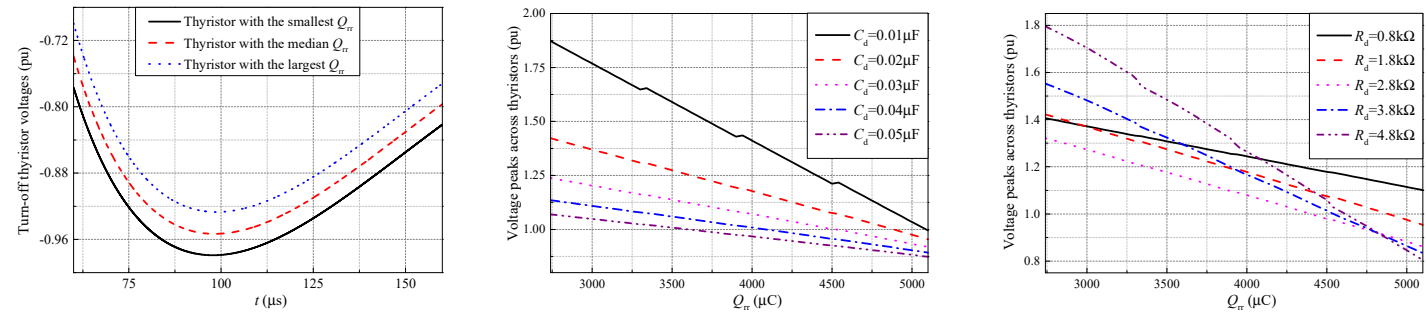

(a) Thyristor voltage distribution due to different $Q_{\mathrm{r}}$ (b) The maximum thyristor voltage under different $C_{\mathrm{d}}$ (c) The maximum thyristor voltage under different $R_{\mathrm{d}}$

Figure 8. Characteristics of Unbalanced Voltage Distribution of Converter Valve.

Thus, the damping circuit parameter design should also consider the commutation overshoot and the forward voltage rise rate at the thyristor level when the unbalanced voltage distribution in the converter valve is taken into account, which cannot be completed by the analytical method.

\subsection{Summary}

According to the above analysis, there exist inevitable conflicts in the parameter design for the damping circuit, if different performance indicators were expected to be optimized separately. For example, the most efficient way to reduce the commutation overshoot is to increase $C_{\mathrm{d}}$, which conversely results in more power losses. At a given $C_{\mathrm{d}}$, if the value of $R_{\mathrm{d}}$ was determined by the optimal resistance, it is not guaranteed that $\mathrm{d} u / \mathrm{d} t_{\max }$ are certainly limited under $\mathrm{d} u / \mathrm{d} t_{\text {lim }}$. Besides, the unbalanced voltage distribution in the converter valve should also be studied for damping circuit parameter design when the dispersion of reverse recovery characteristics is considered. Thus, a synthetical design method should been applied for the damping circuit.

\section{Damping Circuit Parameters Design}

\subsection{Design Characteristics}

The essential of damping circuit parameter design is to make a trade-off between decreasing commutation overshoot and reducing turn-off power losses, on the premise that the maximum valve voltage rise rate does not exceed the limitation. Mathematically this issue can be expressed as a multi-objective optimization problem. One approach for this kind of problem is to construct a comprehensive objective function that demonstrates the overall performance to be optimized. The weighted sum approach method can be used to integrate different performance indicators into the same objective function [36]. However, the physical senses of $U_{\text {ovst }}$ and $P_{\mathrm{L}}$ are totally different. These two quantities with different dimensions should be further transformed for the establishment of an overall objective function. Thus, the concept of economic function is introduced below.

An economic evaluation for a specified UHVDC transmission project takes following four respects into account: construction and equipment investment, operation and maintenance, transmission losses, and interruption costs. The commutation overshoot has important influences on PCOV and the insulation level of the converter valve, which is directly related to the equipment investment. The turn-off power losses result in considerable transmission losses cost. In addition, it is one of the factors considered to determine the capacity of cooling equipment and thus affects the equipment investment indirectly. So, in the economy sense, an objective function composed of economic functions for performance indicators can be established:

$$
f(x)=E_{\mathrm{o}}\left(U_{\mathrm{ovst}}(x)\right)+E_{\mathrm{L}}\left(P_{\mathrm{L}}(\boldsymbol{x})\right)+E_{\mathrm{c}}(\boldsymbol{x})
$$

where $x$ is the variable vector to be optimized, i.e., $\left(R_{\mathrm{d}}, C_{\mathrm{d}}\right) ; E_{\mathrm{O}}$ and $E_{\mathrm{L}}$ are economic functions of the commutation overshoot $U_{\text {ovst }}$ and the turn-off power losses $P_{\mathrm{L}}$. Another economic function $E_{\mathrm{c}}$ in (1) represent the part of equipment investment corresponding to damping circuits. Generally, the value of 
$E_{\mathrm{c}}$ has nothing to do with $R_{\mathrm{d}}$, since the cost of damping resistors is negligible compared with that of damping capacitors.

Note that the unbalanced voltage distribution results in the necessity of device capacity margin and affects the selection of valve grading capacitance. To evaluate the impact of unbalanced voltage distribution, an economic function $E_{\mathrm{u}}$ is added to the objective function:

$$
f(\boldsymbol{x})=E_{\mathrm{o}}\left(U_{\mathrm{ovst}}(\boldsymbol{x})\right)+E_{\mathrm{L}}\left(P_{\mathrm{L}}(\boldsymbol{x})\right)+E_{\mathrm{c}}(\boldsymbol{x})+E_{\mathbf{u}}\left(\frac{U_{\text {Tmax }}(\mathbf{x})-U_{\text {Tmin }}(\mathbf{x})}{U_{\mathrm{ovst}}(\mathbf{x})}\right)
$$

where $U_{\operatorname{Tmax}}(x)$ and $U_{\operatorname{Tmin}}(x)$ refer to the maximum and the minimum thyristor voltages respectively. The term $\left(U_{\operatorname{Tmax}}(x)-U_{\mathrm{Tmin}}(x)\right) / U_{\mathrm{ovst}}(x)$ represents the degree of voltage imbalance.

Now, the parameter design of damping circuit can be described as a constrained multi-variable optimization problem with the following mathematical form:

(P) minimize $f(\mathbf{x})$

$$
\begin{gathered}
\text { subjecttod } u / \mathrm{d} t_{\max }<\mathrm{d} u / \mathrm{d} t_{\lim } \\
R_{\mathrm{d}}>0, C_{\mathrm{d}}>0
\end{gathered}
$$

Additionally, $\mathrm{d} u / \mathrm{d} t_{\max }$ here may refer to the maximum forward voltage rise rate either at the valve level or at the thyristor level under different considerations.

\subsection{Optimization Algorithm}

According to the availability of the derivatives of the objective function, optimization algorithms can be divided into two groups: the indirect search method and the direct search method. In the indirect search method, the Jacobian matrix of the objective function is solved firstly to obtain the extremum that is a candidate for the optimal result. Then this extremum should be substituted into the Hessian matrix for further verification. Although the optimization process convergence quickly, this method is still non-robust and time-consuming as the establishment and solution of the Jacobian matrix and the Hessian matrix is generally very difficult. Importantly, the derivatives of the objective function must be available in the indirect search method. However, it is not the case when the broadband model is applied.

The complex calculation circuit of the broadband model can be solved accurately through numerical calculation methods. Only the value of the objective function can be obtained in this way, where the indirect search method does not work. The direct search method, also called as the derivative-free algorithm, needs no more information about the objective function and continuously searches for the optimal point based on historical results and specific search rules. Despite the existence of iterations, it can be carried out in computer programs with high automation and convergency. Intelligent algorithms, including the genetic algorithm (GA), the particle swarm optimization (PSO), and so on, are representatives which are widely used currently for large scale nonlinear optimization problems. However, it is inappropriate to use these complex algorithms to deal with relatively simple problems such as the parameter design of damping circuit.

After analysis, a simple but efficient optimization algorithm — the nonlinear simplex method-was adopted in this paper. This method originates from the concept 'evolutionary operation' proposed by Box et al. [37], established by Spendley et al. [38] and developed for computer programming by Nelder and Mead [39]. Although researchers have modified some algorithm details for specific applications later $[40,41]$, the core idea has remained unchanged.

Assuming that there are $n$ variables, denoted as the variable vector $x$, to be optimized. $f(x)$ represents the objective function to be minimized. In the $n$-dimensional variable space, an initial simplex composed of $n+1$ points should be determined firstly. The point set of the simplex at the $k_{\text {th }}$ iteration step are denoted as $P_{i}^{k}(1 \leq i \leq n+1)$. Procedures for optimization are presented as follows: 
Step 1. Reflection. According to the simplex at the previous iteration step $k$, a new point $P_{n+2}^{k+1}$ can be calculated as:

$$
P_{n+2}^{k+1}=(1+\alpha) \overline{P^{k}}-\alpha P_{\max }^{k}
$$

where $P_{\max }^{k}$ is the point with the maximum objective function in the $k_{\mathrm{th}}$ iteration step; $\overline{P^{k}}$ is the centroid of the $k_{\text {th }}$ simplex excluding $P_{\max }^{k} ; \alpha$ is a positive constant referred to as the reflection coefficient. $P_{n+2}^{k+1}$ will take place of $P_{\max }^{k}$ for the next iteration step with remaining points.

Step 2. Expansion. After reflection, if $f\left(P_{n+2}^{k+1}\right)<f\left(P_{\min }^{k}\right)$, where $P_{\text {min }}^{k}$ corresponds to the point with the minimum objective function in the $k_{\mathrm{th}}$ step, it indicates that a preferable point may exist at a longer distance in this search direction. So, a potential point $P P_{n+2}^{k+1}$ is calculated as below:

$$
P P_{n+2}^{k+1}=\gamma P_{n+2}^{k+1}+(1-\gamma) \overline{P^{k}}
$$

where $\gamma$ is a constant greater than 1.0 defined as the expansion coefficient. If $f\left(P P_{n+2}^{k+1}\right)<f\left(P_{n+2}^{k+1}\right)$, $P P_{n+2}^{k+1}$ will replace $P_{n+2}^{k+1}$ to go into the next iteration step. Otherwise, $P P_{n+2}^{k+1}$ will be abandoned.

Step 3. Contraction. After reflection, if $f\left(P_{n+2}^{k+1}\right)>f\left(P_{\text {sub }}^{k}\right)$, where $P_{\text {sub }}^{k}$ corresponds to the point with the submaximal objective function in the $k_{\text {th }}$ simplex, it indicates that a preferable point may exist at a shorter distance in this search direction. The potential point $P P_{n+2}^{k+1}$ is calculated as below:

$$
P P_{n+2}^{k+1}=\beta P_{\mathrm{v}}^{k}+(1-\beta) \overline{P^{k}}
$$

where $\beta$ is a constant between 0.0 and 1.0 defined as the contraction coefficient; $P_{\mathrm{v}}^{k}$ is either $P_{n+2}^{k+1}$ or $P_{\max }^{k}$, whichever has the lower function value. If $f\left(P P_{n+2}^{k+1}\right)>\min \left(f\left(P_{n+2}^{k+1}\right), f\left(P_{\max }^{k}\right)\right)$, then $P P_{n+2}^{k+1}$ will replace $P_{n+2}^{k+1}$ for following iterations.

Step 4. Scaling. After contraction, if $f\left(P P_{n+2}^{k+1}\right)>\min \left(f\left(P_{n+2}^{k+1}\right), f\left(P_{\max }^{k}\right)\right)$, it indicates that the current simplex is too large to get closer to the optimal point. Thus, the simplex shrinks to half of the original:

$$
P_{i}^{k+1}=\left(P_{i}^{k}+P_{j}^{k}\right) / 2,(i \neq j, 1 \leq i, j \leq n+1)
$$

where $P_{i}^{k+1}$ is the new point produced by any two adjacent points $P_{i}^{k}$ and $P_{j}^{k}$. Then the optimization process continues with the new point set $P_{i}^{k+1}(1 \leq i \leq \mathrm{n})$.

Step 5. Convergence test. Repeating Step 1-4, the new formed simplex gradually moves to the neighborhood of the optimal point. The search process stops when the pre-set convergence condition (8) is satisfied. Standard deviation of function values in the simplex is used here.

$$
\sqrt{\frac{\sum_{i=1}^{n+1}\left(f\left(P_{i}^{k}\right)-\overline{f^{k}}\right)}{n}}<\varepsilon
$$

The flow chart of the optimization method is outlined in Figure 9. For inequality constraints, the augmented objective function $F(x)$ is formed as:

$$
F(x)=f(x)+p(x)
$$

where $p(x)$ is the term of penalty function determined by the expressions of constraint conditions. The $p(x)$ is set here to prevent invalid searches beyond the feasible region. Then, the augmented form of the objective function will be substituted into $(5) \sim(9)$ to construct a constrained optimization. 


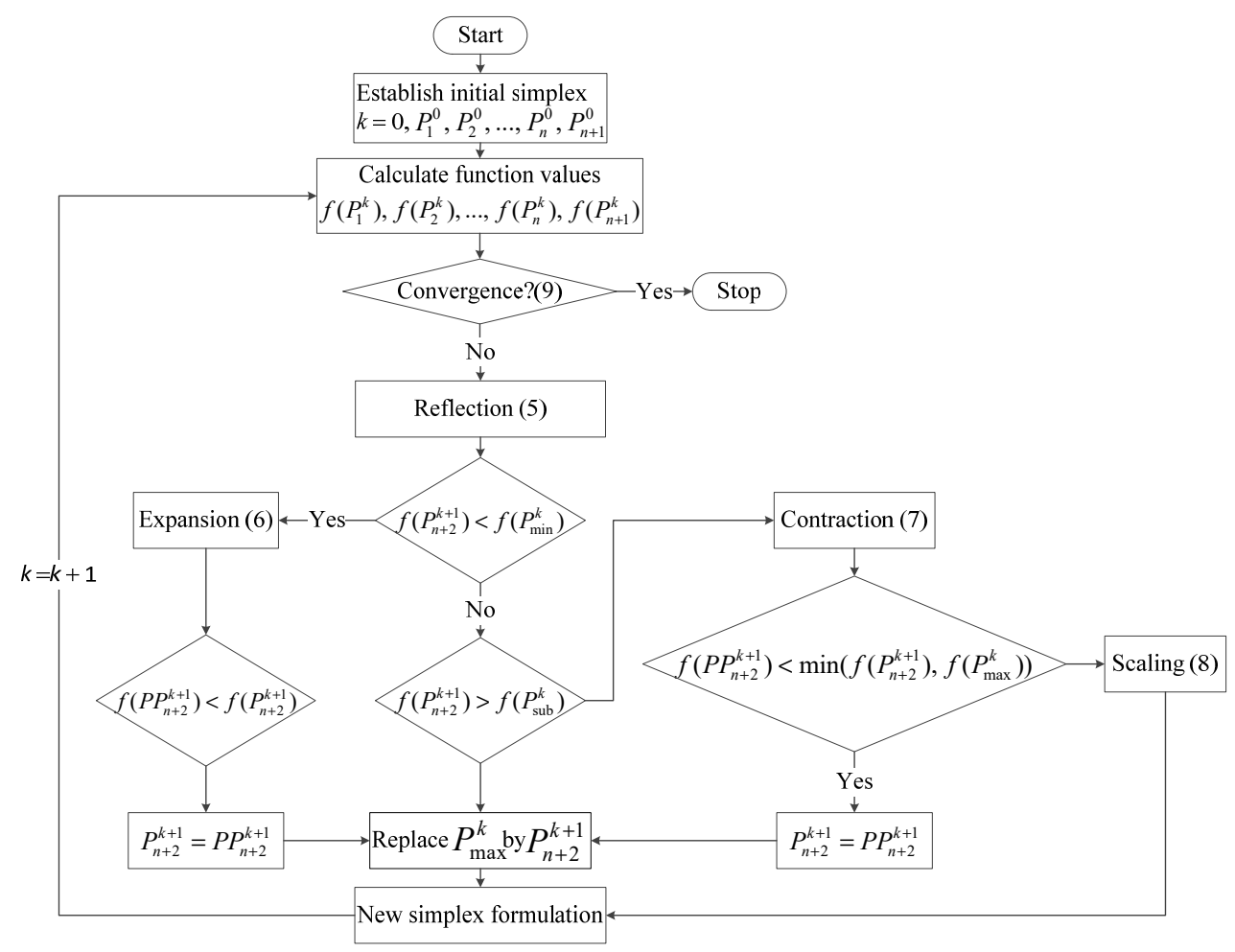

Figure 9. Algorithm Flow Chart.

\section{Case Study}

\subsection{Problem Formulation}

The design case presented here also refers to the $\pm 1100 \mathrm{kV}$ UHVDC project mentioned in previous sections. An augmented objective function $F(x)$ of this design problem is proposed:

$$
F(x)=f(x)+p_{1}\left(\mathrm{~d} v / \mathrm{d} t_{\max }\right)+p_{2}(x)
$$

where $p_{1}$ and $p_{2}$ are penalty functions associated with (3) and (4), established as (12) and (13):

$$
\begin{gathered}
p_{1}(d v / d t)=\left\{\begin{array}{cc}
0, & d v / d t_{\max }<d v / d t_{\lim } \\
a\left(d v / d t_{\max }-d v / d t_{\lim }\right), & d v / d t_{\max }>d v / d t_{\lim }
\end{array}\right. \\
p_{2}(\boldsymbol{x})= \begin{cases}0, & R_{\mathrm{d}} \geq 0, C_{\mathrm{d}} \geq 0 \\
b R_{\mathrm{d}}, & R_{\mathrm{d}}<0, C_{\mathrm{d}} \geq 0 \\
b C_{\mathrm{d}}, & R_{\mathrm{d}} \geq 0, C_{\mathrm{d}}<0 \\
b\left(R_{\mathrm{d}}+C_{\mathrm{d}}\right), & R_{\mathrm{d}}<0, C_{\mathrm{d}}<0\end{cases}
\end{gathered}
$$

where $a$ and $b$ are constant punish coefficients that are designated as 1000.0 in this case. In order to limit the bad effect of different numerical sizes of variables on the optimization algorithm, the units of $R_{\mathrm{d}}$ and $C_{\mathrm{d}}$ should be set as $\mathrm{k} \Omega$ and $\mu \mathrm{F}$, respectively. The values of $U_{\mathrm{ovst}}, P_{\mathrm{L}}$, and $\mathrm{d} v / \mathrm{d} t_{\mathrm{max}}$ are calculated based on the broadband model by EMT program.

In practice, detailed researches should be done to determine adequate economic functions. Here, linear functions are used to demonstrate the principle of the proposed optimization method:

$$
E_{\mathrm{o}}\left(U_{\text {ovst }}(x)\right)=w_{1} U_{\text {ovst }}(x), E_{\mathrm{L}}\left(P_{\mathrm{L}}(\boldsymbol{x})\right)=w_{2} P_{\mathrm{L}}(\boldsymbol{x}), E_{\mathrm{c}}(\boldsymbol{x})=w_{3} C_{\mathrm{d}}, E_{\mathrm{u}}(\boldsymbol{x})=w_{4}\left(\frac{U_{\mathrm{T} \max }(x)-U_{\mathrm{T} \min }(x)}{U_{\mathrm{ovst}}(\boldsymbol{x})}\right)
$$


where $w_{1}, w_{2}, w_{3}$, and $w_{4}$ are proportionality coefficients. According to engineering experiences, the values of $w_{1}, w_{2}, w_{3}$, and $w_{4}$ are set as $0.3,30,5$, and 40 .

Three important parameters for the optimization algorithm are the reflection coefficient $\alpha$, the expansion coefficient $\gamma$, and the contraction coefficient $\beta$. According to parameter sensitivity study carried out in [42], we choose 1.0, 2.0, and 0.5 as the values of $\alpha, \gamma$, and $\beta$, respectively. Besides, the convergent limit $\varepsilon$ is set as 0.05 .

Before the search process start, an initial simplex should be established. As the variable space is a two-dimensional plane, where $R_{\mathrm{d}}$ is selected as the $\mathrm{x}$-axis and $C_{\mathrm{d}}$ is selected as the y-axis, the simplex takes a form of triangle. Specifically, we chose an isosceles triangle to be the initial simplex.

\subsection{Optimization Results Considering Balanced Voltage Distribution}

In this section, it is assumed that all thyristors have the same reverse recovery process and the objective function to be optimized is in the form of (1). Repeated optimization experiments are carried out for the same objective function and constraint conditions. The difference is these optimization processes start from different initial simplex, which are evenly distributed in a wide region, i.e., $R_{\mathrm{d}} \in[1000 \Omega, 5000 \Omega]$ and $C_{\mathrm{d}} \in[0.01 \mu \mathrm{F}, 0.05 \mu \mathrm{F}]$. As can be seen from Table 1, all five optimization processes converge to the same small area, which demonstrates a good convergence of the proposed optimization method. The optimized parameters are $R_{\mathrm{d}}=2000 \Omega$ and $C_{\mathrm{d}}=0.025 \mu \mathrm{F}$.

Table 1. Summary of Optimization Results Considering Balanced Voltage Distribution.

\begin{tabular}{cccc}
\hline Initial Simplex & Termination Point & Iterations & $f(x)$ \\
\hline$(1.0,1.0),(1.0,1.5),(1.5,1.0)$ & $(2.02,2.55)$ & 49 & 92.99 \\
\hline$(2.0,2.0),(2.0,2.5),(2.5,2.0)$ & $(2.02,2.53)$ & 46 & 92.99 \\
\hline$(3.0,3.0),(3.0,3.5),(3.5,3.0)$ & $(2.02,2.54)$ & 48 & 92.99 \\
\hline$(4.0,4.0),(4.0,4.5),(4.5,4.0)$ & $(2.01,2.52)$ & 43 & 93.00 \\
\hline$(5.0,5.0),(5.0,5.5),(5.5,5.0)$ & $(2.00,2.45)$ & 55 & 93.02 \\
\hline
\end{tabular}

To further illustrate the principle of the proposed optimization method, Figure 10 depicts the development traces of parameter points starting from different initial simplex. Numbers tagged to points represent the order that they appear in the optimization process. When the current simplex stays away from the optimal point (see Figure 10a), the main evolution modes are reflection and expansion. The search process advances in an explicit direction and get close to the neighborhood of the optimal point quickly. When the current simplex is close to the optimal point (see Figure 10b), the main evolution modes are contraction and scaling. The area of new formed simplex decreases continuously and the new produced point gradually approaches to the optimal point, until the optimization process is stopped when the convergence condition is satisfied.

Table 2 makes a comparison between the practical damping circuit parameters (in the second row) and the optimized ones (in the third row). Giving a high priority to safe operation, the practical parameter setting tends to get lower commutation overshoots and valve voltage rise rate. However, greater power losses with higher economic cost arise from the selection of a larger damping capacitance. Contrarily, the optimized result pays more attention to the overall economic benefits, with the commutation overshoots and valve voltage rise rate increased but limited under the acceptable level.

Table 2. Comparison Between The Practical and The Optimized Parameters.

\begin{tabular}{cccccc}
\hline Item & $\boldsymbol{R}_{\mathbf{d}}(\mathbf{k} \mathbf{\Omega})$ & $C_{\mathbf{d}}\left(\times \mathbf{1 0}^{-\mathbf{2}} \boldsymbol{\mu F}\right)$ & $\mathbf{d} u / \mathbf{d} t_{\max }(\mathbf{k V} / \mu \mathbf{s})$ & $k_{\text {ovst }}$ & $f(x)$ \\
\hline Practical & 1.8 & 3.0 & 3.65 & 1.14 & 93.95 \\
\hline Theoretical & 2.0 & 2.5 & 3.97 & 1.15 & 93.03 \\
\hline
\end{tabular}




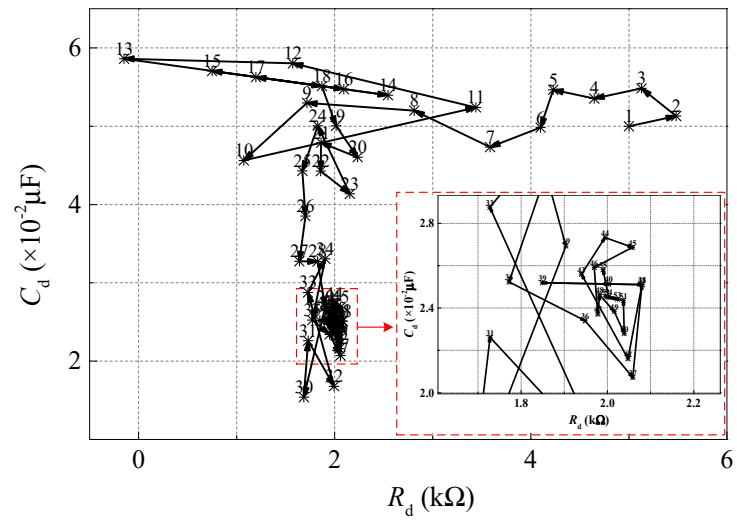

(a) Optimization process starting from $(5.0,5.0),(5.5,5.0),(5.0,5.5)$

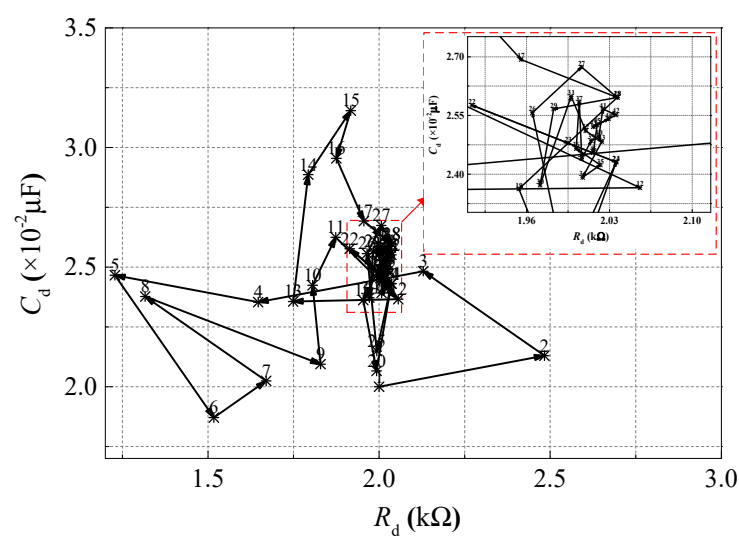

(a) Optimization process starting from $(2.0,2.0),(2.5,2.0),(2.0,2.5)$

Figure 10. Optimization Processes from Different Initial Simplex.

\subsection{Parameter Optimization Considering Unbalanced Voltage Distribution}

In this section, the unbalanced voltage distribution arising from device dispersion is considered in damping circuit parameter design and the selected objective function is in the form of (2). Comparative studies have been carried out under assumptions for different distribution ranges of $Q_{\text {rr }}$, i.e., $\pm 5 \%$ and $\pm 10 \%$. The optimization results are shown in Tables 3 and 4 .

Table 3. Optimization Results Considering Unbalanced Voltage Distribution ( $\pm 5 \% Q_{\text {rr }}$ Distribution).

\begin{tabular}{cccc}
\hline Initial Simplex & Termination Point & Iterations & $f(x)$ \\
\hline$(1.0,1.0),(1.0,1.5),(1.5,1.0)$ & $(1.98,2.59)$ & 53 & 98.57 \\
\hline$(2.0,2.0),(2.0,2.5),(2.5,2.0)$ & $(1.96,2.68)$ & 56 & 98.53 \\
\hline$(3.0,3.0),(3.0,3.5),(3.5,3.0)$ & $(1.95,2.66)$ & 49 & 98.53 \\
\hline$(4.0,4.0),(4.0,4.5),(4.5,4.0)$ & $(1.96,2.70)$ & 52 & 98.56 \\
\hline$(5.0,5.0),(5.0,5.5),(5.5,5.0)$ & $(1.97,2.65)$ & 55 & 98.55 \\
\hline
\end{tabular}

Table 4. Optimization Results Considering Unbalanced Voltage Distribution ( $\pm 10 \% Q_{\mathrm{rr}}$ Distribution).

\begin{tabular}{cccc}
\hline Initial Simplex & Termination Point & Iterations & $f(x)$ \\
\hline$(1.0,1.0),(1.0,1.5),(1.5,1.0)$ & $(1.88,2.95)$ & 59 & 106.32 \\
\hline$(2.0,2.0),(2.0,2.5),(2.5,2.0)$ & $(1.88,2.94)$ & 57 & 106.37 \\
\hline$(3.0,3.0),(3.0,3.5),(3.5,3.0)$ & $(1.90,2.93)$ & 58 & 106.37 \\
\hline$(4.0,4.0),(4.0,4.5),(4.5,4.0)$ & $(1.84,2.97)$ & 60 & 106.36 \\
\hline$(5.0,5.0),(5.0,5.5),(5.5,5.0)$ & $(1.85,3.01)$ & 62 & 106.31 \\
\hline
\end{tabular}

The optimization information given in above tables have shown a good convergence when $E_{\mathrm{u}}$ is added to the objective function. As can be seen, a larger damping capacitance is preferred to limit the degree of voltage imbalance due to wider distribution range of $Q_{\mathrm{rr}}$. The variation of damping resistance is relatively small, since it is not critical for the unbalanced voltage distribution. This effect has been illustrated in Figure 8. Table 5 summarizes the optimization results derived from different considerations for the dispersity of $Q_{\mathrm{rr}}$. Though the optimized parameters vary, it is found that little difference can be observed between cases in which the balanced voltage distribution is considered or the $Q_{\text {rr }}$ distribution range stays within $\pm 5 \%$. 
Table 5. Comparisons of Optimized Parameters Considering Different $Q_{\mathrm{rr}}$ Distribution Ranges.

\begin{tabular}{cccccc}
\hline Distribution & $\boldsymbol{R}_{\mathbf{d}}(\mathbf{k} \Omega)$ & $C_{\mathbf{d}}\left(\times \mathbf{1 0}^{-\mathbf{2}} \boldsymbol{\mu F}\right)$ & $\mathbf{d} u / \mathbf{d} t_{\max }(\mathbf{k V} / \mu \mathbf{s})$ & $k_{\text {ovst }}$ & $f(x)$ \\
\hline 0 & 2.0 & 2.5 & 3.97 & 1.15 & 93.03 \\
\hline $\pm 5 \%$ & 1.95 & 2.66 & 3.97 & 1.15 & 98.53 \\
\hline $\pm 10 \%$ & 1.85 & 3.01 & 3.99 & 1.14 & 106.31 \\
\hline
\end{tabular}

\subsection{Analysis of Economic Functions}

Above, economic functions of the linear form are adopted for optimization. The function parameters are determined according to engineering practice. Since the forms and parameters of economic functions may be changed under specific considerations, it is necessary to study the adaptability of the proposed optimization method to various economic functions. For brief explanation, optimizations based on balanced voltage distribution is adopted in this section.

In the optimization process, different priorities are given to different performance indicators by adjusting the relative values of weighting coefficients. Table 6, Table 7, Table 8 has compared the optimized results under different $w_{1}, w_{2}$, and $w_{3}$. For the sake of analysis, the others remain unchanged when one of them varies. As can be seen from Tables 2 and 6 , a larger $w_{1}$ indicates that the main purpose of the optimization is to reduce commutation overshoots. Thus, the optimized results tend to increase the damping capacitance to get lower commutation overshoots, which inevitably cause higher turn-off power losses. On the contrary, if the optimization pays more attention to the power losses and the investment of damping circuits, $w_{2}$ and $w_{3}$ should be increased, so that small damping capacitances would occur in the optimized results which corresponds to higher commutation overshoots, as shown in Tables 7 and 8. Noted that the variation of $R_{\mathrm{d}}$ in the optimized results is much smaller than that of $C_{\mathrm{d}}$, since the value of damping resistance is strictly limited by the requirement of $\mathrm{d} u / \mathrm{d} t_{\text {lim }}$.

Table 6. Effects of $w_{1}$ on Optimization Results.

\begin{tabular}{ccccc}
\hline $\boldsymbol{w}_{\mathbf{1}}$ & $\boldsymbol{R}_{\mathbf{d}}(\mathbf{k} \boldsymbol{\Omega})$ & $\boldsymbol{C}_{\mathbf{d}}\left(\times \mathbf{1 0}^{-\mathbf{2}} \boldsymbol{\mu F}\right)$ & $\boldsymbol{P}_{\mathbf{L}}\left(\times \mathbf{1 0}^{-\mathbf{4}} \mathbf{p u}\right)$ & $\boldsymbol{k}_{\text {ovst }}$ \\
\hline 0.1 & 3.29 & 0.83 & 3.87 & 1.29 \\
\hline 0.6 & 1.87 & 3.21 & 6.31 & 1.13 \\
\hline 0.9 & 1.71 & 4.28 & 7.40 & 1.11 \\
\hline
\end{tabular}

Table 7. Effects of $w_{2}$ on Optimization Results.

\begin{tabular}{ccccc}
\hline$w_{\mathbf{2}}$ & $\boldsymbol{R}_{\mathbf{d}}(\mathbf{k} \Omega)$ & $C_{\mathbf{d}}\left(\times \mathbf{1 0}^{-\mathbf{2}} \boldsymbol{\mu F}\right)$ & $\boldsymbol{P}_{\mathbf{L}}\left(\times \mathbf{1 0}^{-\mathbf{4}} \mathbf{p u}\right)$ & $\boldsymbol{k}_{\text {ovst }}$ \\
\hline 15 & 2.32 & 1.95 & 5.01 & 1.17 \\
\hline 60 & 2.39 & 1.77 & 4.83 & 1.18 \\
\hline 90 & 2.44 & 1.68 & 4.74 & 1.19 \\
\hline
\end{tabular}

Table 8. Effects of $w_{3}$ on Optimization Results.

\begin{tabular}{ccccc}
\hline$w_{3}$ & $\boldsymbol{R}_{\mathbf{d}}(\mathbf{k} \Omega)$ & $C_{\mathbf{d}}\left(\times \mathbf{1 0}^{-\mathbf{2}} \boldsymbol{\mu F}\right)$ & $\boldsymbol{P}_{\mathbf{L}}\left(\times \mathbf{1 0}^{-\mathbf{4}} \mathbf{p u}\right)$ & $\boldsymbol{k}_{\text {ovst }}$ \\
\hline 2.5 & 1.95 & 2.98 & 6.07 & 1.14 \\
\hline 7.5 & 2.65 & 1.41 & 4.46 & 1.20 \\
\hline 10 & 2.88 & 1.14 & 4.19 & 1.23 \\
\hline
\end{tabular}

In linear form, the objective function to be minimized is represented as the weighted sum of turn-off performances indicators. Sometimes there is the necessity to change the forms of economic functions. For example, it is reasonable to set $E_{\mathrm{O}}$ and $E_{\mathrm{L}}$ as quadratic functions considering that the 
difficulty of equipment manufacturing increases nonlinearly with the increase of voltage and power capacities. Since a large damping capacitance can be obtained by serval parallelly connected small capacitances, the nonlinearity of $E_{\mathrm{c}}$ is implicit and it is still expressed by a linear function. Thus, the new objective function can be expressed as:

$$
f(\boldsymbol{x})=w_{1}\left(U_{\mathrm{ovst}}(\boldsymbol{x})\right)^{2}+w_{2}\left(P_{\mathrm{loss}}(\boldsymbol{x})\right)^{2}+w_{3} C_{\mathrm{d}}
$$

Table 9 summaries the optimization results with different initial simplex. All five optimization processes converge to the same small region inside which the optimized point is $(1.8,3.0)$. It can be seen that the proposed optimization method can be effectively applied to situations where the economy functions are nonlinear.

Table 9. Summary of Optimization Results Based on Quadratic Functions.

\begin{tabular}{cccc}
\hline Initial Simplex & Termination Point & Iterations & $f(x)$ \\
\hline$(1.0,1.0),(1.0,1.5),(1.5,1.0)$ & $(1.80,2.98)$ & 66 & 123.56 \\
\hline$(2.0,2.0),(2.0,2.5),(2.5,2.0)$ & $(1.80,3.01)$ & 54 & 123.53 \\
\hline$(3.0,3.0),(3.0,3.5),(3.5,3.0)$ & $(1.80,3.01)$ & 60 & 123.54 \\
\hline$(4.0,4.0),(4.0,4.5),(4.5,4.0)$ & $(1.81,3.04)$ & 65 & 123.53 \\
\hline$(5.0,5.0),(5.0,5.5),(5.5,5.0)$ & $(1.81,3.02)$ & 60 & 123.51 \\
\hline
\end{tabular}

\section{Conclusions}

In this paper, the turn-off performances of converter valve have been analyzed by the broadband model firstly. Moreover, a reliable and flexible method for damping circuit parameters design are proposed. The main conclusions are presented below:

1. During the turn-off process of converter valve, the analytical calculation for the transient valve voltage has a low accuracy due to the application of low-frequency equipment models. High frequency parameters of valve equipment have non-negligible effects on the turn-off process, which are important for the damping circuit design. Thus, it is suggested to adopt the broadband model to evaluate the turn-off performances of converter valve based on numerical calculation methods.

2. There are inevitable conflicts existing in the parameters design of the damping circuit so that the turn-off performances cannot be optimized simultaneously. Besides, the unbalanced voltage distribution in the converter valve should also be studied for damping circuit parameter design. The damping circuit parameter design is essentially a constrained multi-objective optimization problem.

3. Parameters of the damping circuit can be optimized by the proposed optimization method consisting of EMT numerical calculation and the nonlinear simplex method. The concept of economic function is proposed to form a comprehensive objective function. The case study shows that the proposed optimization method has a good convergency.

4. The forms and parameters of economic functions can be adjusted according to the requirement of practical engineering. The optimization results presented in Section 5 have verified the reliability and flexibility of the proposed optimization method.

Author Contributions: Conceptualization, Z.X.; Methodology, Y.T. and Z.Z.; Validation, Y.T. and Z.Z.; Formal Analysis, Y.T.; Investigation, Y.T., Z.Z., and Z.X.; Writing-Review and Editing, Y.T., Z.Z., and Z.X.; Supervision, Z.X. and Z.Z. All authors have read and agreed to the published version of the manuscript.

Funding: This research received no external funding.

Conflicts of Interest: The authors declare no conflict of interest. 


\section{Abbreviations}

The following abbreviations are used in this manuscript:

$\mathrm{AC}$

$\mathrm{DC}$

Alternating current

HVDC

Direct current

UHVDC

High voltage direct current

LCC

Ultra high voltage direct current

PCOV

Line commutated converter

EMT

Peak value of continuous operating voltage

PCC

Electromagnetic transient

$Z_{\mathrm{C}}$

$\mathrm{V}_{1} \sim \mathrm{V}_{6}$

Point of common coupling

$R_{\mathrm{d}}$ and $C_{\mathrm{d}}$

Common impedance at point of common coupling

$i_{\mathrm{r}}(t)$

$U_{\text {ovst }}$

$\mathrm{d} u / \mathrm{d} t$

Converter valve, subscripts represent valve numbers

$P_{\mathrm{L}}$

$Q_{\mathrm{rr}}$

$t_{\mathrm{rr}}$

Parameters of damping circuit: damping resistance and damping capacitance

Reverse recovery current

Commutation overshoot

Forward valve voltage rise rate

Power losses during valve turn-off process

Reverse recovery charge

Reverse recovery time

$E_{\mathrm{L}} \quad$ Economic functions for power losses

$E_{\mathrm{O}} \quad$ Economic functions for commutation overshoot

$E_{\mathrm{C}} \quad$ Economic functions for damping circuit investments

$E_{\mathrm{u}} \quad$ Economic functions for unbalanced voltage distribution

$w_{1} \sim w_{4} \quad$ Constant coefficient of economic functions

$a$ and $b \quad$ Constant punish coefficients

$\alpha, \gamma$ and $\beta \quad$ Algorithm parameters: reflection, expansion and contraction coefficients

\section{Appendix A}

Main parameters of the referenced $\pm 1100 \mathrm{kV}$ HVDC project are as follows:

Table A1. Model Parameters of The Referenced \pm 1100 kV HVDC Project.

\begin{tabular}{ccc}
\hline System/Equipment & Parameters & Values \\
\hline \multirow{3}{*}{ AC switchyard } & Rated voltage $\left(E_{\mathrm{v}} / \sqrt{2}\right)$ & $750 \mathrm{kV}$ \\
\cline { 2 - 3 } & Short circuit capacity & $63 \mathrm{kA}$ \\
\cline { 2 - 3 } & Reactive compensation capacity & $6700 \mathrm{MVA}$ \\
\cline { 2 - 3 } & Transformer ratio & $750 \mathrm{kV} / 235 \mathrm{kV}$ \\
\cline { 2 - 3 } Converter transformer & 2-phase transformer capacity & $1800 \mathrm{MVA}$ \\
\cline { 2 - 3 } & Leakage reactance $\left(L_{\mathrm{t} 1}+L_{\mathrm{t} 2}\right)$ & $0.02 \mathrm{H}$ \\
\cline { 2 - 3 } & Winding resistance $\left(R_{\mathrm{t} 1}+R_{\mathrm{t} 2}\right)$ & $27 \Omega$ \\
\cline { 2 - 3 } & Stray inductance $L_{\mathrm{ts}}$ & $2 \mathrm{mH}$ \\
\cline { 2 - 3 } & Stray capacitances inside windings $C_{\mathrm{t} 1} / C_{\mathrm{t} 2}$ & $10 / 3.8 \mathrm{nF}$ \\
\cline { 2 - 3 } & Stray capacitances to ground $C_{\mathrm{t} 1 \mathrm{~g}} / C_{\mathrm{t} 2 \mathrm{~g}}$ & $16.99 / 3.31 \mathrm{nF}$ \\
\hline \multirow{2}{*}{ Wall bushing } & Stray capacitance at valve side windings $C_{\mathrm{bt}}$ & $1.91 \mathrm{nF}$ \\
& Stray capacitance at pole lines $C_{\mathrm{bp}}$ & $0.4 \mathrm{nF}$ \\
\cline { 2 - 3 } & &
\end{tabular}


Table A1. Cont.

\begin{tabular}{|c|c|c|c|}
\hline System/Equipment & \multicolumn{2}{|c|}{ Parameters } & Values \\
\hline \multirow{16}{*}{ Converter valve } & \multicolumn{2}{|c|}{ Rated voltage } & $1100 \mathrm{kV}$ \\
\hline & \multicolumn{2}{|c|}{ Rated transmission power } & 12000MW \\
\hline & \multicolumn{2}{|c|}{ Smoothing inductance } & $75 \mathrm{mH}$ \\
\hline & \multirow{5}{*}{ Saturable reactor } & Winding resistance $R_{\mathrm{s} 0}$ & $0.1 \mathrm{~m} \Omega$ \\
\hline & & Air core inductance $L_{\mathrm{s} 0}$ & $6.3 \mu \mathrm{F}$ \\
\hline & & Core loss resistance $R_{\mathrm{sm}}$ & $0.32 \mathrm{~m} \Omega$ \\
\hline & & Magnetizing inductance $L_{\mathrm{sm}}$ & $2.8 \mathrm{mH}$ \\
\hline & & Stray capacitance $C_{\mathrm{s}}$ & $5.0 \mathrm{nF}$ \\
\hline & \multirow{5}{*}{ Thyristorcircuits } & DC grading resistance $R_{\mathrm{tdc}}$ & $5.76 \mathrm{M} \Omega$ \\
\hline & & Damping resistance $R_{\mathrm{d}}$ & $1800 \Omega$ \\
\hline & & Damping capacitance $C_{\mathrm{d}}$ & $0.03 \mu \mathrm{F}$ \\
\hline & & Reverse recovery charge $Q_{\mathrm{rr}}$ & $3900 \mu \mathrm{C}$ \\
\hline & & Distribution range of $Q_{\mathrm{rr}}$ & $\pm 5 \%$ \\
\hline & \multicolumn{2}{|c|}{ Grading capacitance $C_{\mathrm{g}}$} & $1.0 \mathrm{uF}$ \\
\hline & \multicolumn{2}{|c|}{ Stray capacitances between components $C_{\mathrm{vv}}$} & $120 \mathrm{pF}$ \\
\hline & \multicolumn{2}{|c|}{ Stray capacitances to ground $C_{\mathrm{vg}}$} & $200 \mathrm{pF}$ \\
\hline \multirow{5}{*}{ Smoothing reactor } & \multicolumn{2}{|c|}{ Main inductance $L_{\mathrm{L}}$} & $75 \mathrm{mH}$ \\
\hline & \multicolumn{2}{|c|}{ winding resistance } & $10 \mathrm{~m} \Omega$ \\
\hline & \multicolumn{2}{|c|}{ Stray capacitance at valve side $C_{\mathrm{Lv}}$} & $412.5 \mathrm{pF}$ \\
\hline & \multicolumn{2}{|c|}{ Stray capacitance at valve side $C_{\mathrm{LL}}$} & $412.5 \mathrm{pF}$ \\
\hline & \multicolumn{2}{|c|}{ Stray capacitance across winding $C_{\mathrm{L}}$} & $534 \mathrm{pF}$ \\
\hline \multirow{2}{*}{ DC system } & \multicolumn{2}{|c|}{ Rated voltage $U_{\mathrm{dc}}$} & $1100 \mathrm{kV}$ \\
\hline & \multicolumn{2}{|c|}{ Rated power transmission $P_{\mathrm{n}}$} & $12000 \mathrm{MW}$ \\
\hline
\end{tabular}

\section{References}

1. Jiang, L.; Zhang, L.; Zou, L.; Zhao, T. Investigation on an optimized topology design of the HVDC converter valve to mitigate commutation failure. In Proceedings of the 2016 IEEE 11th Conference on Industrial Electronics and Applications (ICIEA), Hefei, China, 5-7 June 2016; pp. 343-347.

2. Zha, K.; Cao, J.Z.; Ouyang, W.; Sun, B.; Gao, C.; Luan, H. Design of 6250A/ $\pm 800 \mathrm{kV}$ UHVDC converter valve. In Proceedings of the 13th IET International Conference on AC and DC Power Transmission (ACDC 2017), Manchester, UK, 14-16 February 2017; pp. 1-6.

3. Kumar, A.; Jhampati, S.; Suri, R. HVDC Converter Stations Design for LCC Based HVDC Transmission System-Key Consideration. In Proceedings of the 14th IEEE India Council International Conference, Roorkee, India, 15-17 December 2017; pp. 1-6.

4. Gou, R. Research on 1100-kV/5500-A Ultra-High Voltage Thyristor Valve Key Technology and Its Application. IEEE Trans. Power Electron. 2019, 34, 10524-10533. [CrossRef]

5. Woodhouse, M.L. Voltage and Current Stresses on HVDC Valves. IEEE Trans. Power Deliv. 1987, 2, $199-206$. [CrossRef]

6. Yue, K.; Pang, L.; You, H.; Li, S.; Kong, D.; Li, Y.; Zhang, Q.; Liu, L. Reverse recovery characteristics of high power thyristors in HVDC converter valve. IEEE Trans. Dielectr. Electr. Insul. 2017, 24, 2132-2140. [CrossRef]

7. Arrillaga, J.; Ramsbottom, M.J. Commutation transients in h.v.d.c. convertors during normal and abnormal conditions. Proc. Inst. Electr. Eng. 1970, 117, 1324-1332. [CrossRef]

8. Chang, W.L.; Song, B.P. Design of a thyristor snubber circuit by considering the reverse recovery process. IEEE Trans. Power Electron. 1988, 3, 440-446. [CrossRef]

9. Tennakoon, S.B.; Woodhouse, M.L. Calculation of valve damping circuit losses in 12-pulse HVDC convertors. IEEE Trans. Power Deliv. 1992, 7, 1002-1008. [CrossRef] 
10. Ma, C.L.; Lauritzen, P.O.; Turkes, P.; Mattausch, H.J.; Liu, S.; Xu, Z. A physically-based lumped-charge SCR model. In Proceedings of the IEEE Power Electronics Specialist Conference-PESC '93, Seattle, WA, USA, 20-24 June 1993; pp. 53-59.

11. McMurray, W. Optimum Snubbers for Power Semiconductors. IEEE Trans. Ind. Appl. 1972, 5, 593-600. [CrossRef]

12. Burdio, J.M.; Martinez, A. A unified discrete-time state-space model for switching converters. IEEE Trans. Power Electron. 1995, 10, 694-707. [CrossRef]

13. Zhang, J.; Tang, G.; Wen, J.; Zha, K. Dynamic Modelling of the Turn off Performance of High Voltage Power Thyristor. Power Electron. 2015, 49, 50-53. (In Chinese)

14. Revankar, G.N.; Srivastava, P.K. Turnoff Model of an SCR. IEEE Trans. Ind. Electron. Contr. Instrum. 1975, 4, 507-510. [CrossRef]

15. Chokhawala, R.S.; Carroll, E.I. A snubber design tool for P-N junction reverse recovery using a more accurate simulation of the reverse recovery waveform. IEEE Trans. Ind. Appl. 1991, 27, 74-84. [CrossRef]

16. Gao, C.; Zhang, J.; Zhou, J.; Yin, C. Study on the Calculation of the Commutation Overshoot of HVDC Valve Based on the Piecewise Fitting of Reverse Recovery Current of Thyristor. Proc. CSEE 2018, 38, 547-556. (In Chinese)

17. Zhou, P.; He, H.; Dai, M.; Wan, L. Selection of Arresters Arrangement, Parameters and Apparatuses Insulation Levels for $\pm 1100 \mathrm{kV}$ DC Converter Station. High Volt. Eng. 2014, 40, 2871-2884. (In Chinese)

18. Huang, H.; Fang, T.; Liu, L.; Zhang, X.; Chen, C.; Cao, D. Modeling of reverse recovery characteristic and optimal design of resistance and capacitance parameters for thyristor converter valve. Electr. Power Autom. Equip. 2017, 37, 187-190.

19. ABB. Design of RC Snubbers for Phase Control Applications; Application note; ABB: Zurich, Switzerland, 2008; pp. 7-8.

20. Beausejour, Y.; Karady, G. Valve Damping Circuit Design for HVDC Systems. IEEE Trans. Power Appar. Syst. 1973, 5, 1615-1621. [CrossRef]

21. Undeland, T.M.; Petterteig, A.; Hauknes, G.; Adnanes, A.K.; Garberg, S. Diode and thyristor turn-off snubbers simulation by KREAN and an easy to use design algorithm. In Proceedings of the Conference Record of the 1988 IEEE Industry Applications Society Annual Meeting, Pittsburgh, PA, USA, 2-7 October 1988; pp. 647-654.

22. Gole, A.M.; Filizadeh, S.; Menzies, R.W.; Wilson, P.L. Optimization-enabled electromagnetic transient simulation. IEEE Trans. Power Deliv. 2005, 20, 512-518. [CrossRef]

23. Tong, W.; Li, H.; Fu, P.; Song, Z.; Wang, K.; Wang, S.; Zhang, X. Parameter Optimization of Thyristor Snubber Circuit in LSTF Quench Protection System. IEEE Access 2019, 7, 81257-81265. [CrossRef]

24. Karady, J.; Gilsig, T. The Calculation of Turn-off Overvoltages in a High Voltage dc Thyristor Valve. IEEE Trans. Power Appar. Syst. 1972, 2, 565-574. [CrossRef]

25. Qi, L.; Guan, L.; Shuai, Q.; Wen, J.; Cui, X.; Wei, X.; Fang, C. Building and Analysis of Integrated Wideband Models for Key Components in HVDC Converter Valve Systems. IEEE Trans. Electromagn. Compat. 2014, 56, 1697-1706. [CrossRef]

26. Jiao, C.; Yao, A.; Liu, X. Broadband models for key equipment in high-voltage DC converter stations. IET Power Electron. 2016, 9, 1761-1767. [CrossRef]

27. Qi, L.; Shuai, Q.; Cui, X.; Fang, C.; Sun, H.; Wei, X.; Gao, C. Parameter Extraction and Wideband Modeling of $\pm 1100 \mathrm{kV}$ Converter Valve. IEEE Trans. Power Deliv. 2017, 32, 1303-1313. [CrossRef]

28. Valii, M.; Bigdeli, M.; Hojjatiparast, F. Transient model parameters identification of transformer based on PSO algorithm. In Proceedings of the 2013 3rd International Conference on Electric Power and Energy Conversion Systems, Istanbul, Turkey, 2-4 October 2013; pp. 1-5.

29. Zhang, X.; Yu, Z.; He, J.; Wang, Y.; Zeng, R. The broadband frequency characteristics of major equipment in the $\pm 800 \mathrm{kV}$ converter station and their influences to the short-circuit fault transient. Electr. Power Syst. Res. 2017, 147, 302-309. [CrossRef]

30. Ying, C.; Xu, Z.; Luo, C. Analysis of high-frequency interference characteristics of UHVDC converters. J. Eng. 2019, 2019, 1937-1941. [CrossRef]

31. Lou, Y.; Li, Z.; Xie, L.; Wan, L. Research on overvoltage and minimum air clearance on $1000 \mathrm{kV}$ AC side of converter transformer in $\pm 1100 \mathrm{kV}$ Guquan converter station. J. Eng. 2019, 2019, 2159-2164. 
32. IEC 60071-5: Insulation Co-Ordination-Part 5: Procedures for High-Voltage Current (HVDC) Converter Stations; IEC: Geneva, Switzerland, 2014; pp. 28-29.

33. Li, W.; Kong, D.; Yue, K.; Li, S.; Sun, W.; Peng, J.; Wang, K.; Tan, X.; Liu, X.; Zhang, Q.; et al. Study on reverse recovery characteristics of thyristor used in HVDC converter valve. In Proceedings of the 12th IET International Conference on AC and DC Power Transmission (ACDC 2016), Beijing, China, 28-29 May 2016; pp. 1-5.

34. Cepek, M.; Douville, J.; Fecteau, G.; Malewski, R. Loss measurement in high voltage thyristor valves. IEEE Trans. Power Deliv. 1994, 9, 1222-1236. [CrossRef]

35. Lips, H.P. Water cooling of HVDC thyristor valves. IEEE Trans. Power Deliv. 1994, 9, 1830-1837. [CrossRef]

36. Chowdhury, D.; De, B.P.; Maji, K.B.; Ghosh, S.; Kar, R.; Mandal, D. Optimization of Electrical Parameters for the Gate Stack Double Gate (GSDG) MOSFET using Simplex-PSO Algorithm. In Proceedings of the 2019 Devices for Integrated Circuit (DevIC), Kalyani, India, 23-24 March 2019; pp. 334-336.

37. Box George, E.P. Evolutionary Operation: A Method for Increasing Industrial Productivity. J. R. Stat. Soc. Ser. C (Appl. Stat.) 1957, 6, 81-101.

38. Spendley, W.; Hext, G.R.; Himsworth, F.R. Sequential Application of Simplex Designs in Optimisation and Evolutionary Operation. Technometrics 1962, 4, 441-461. [CrossRef]

39. Neleder, J.A.; Mead, R. A simplex method for function minimization. Comput. J. 1965, 7, 308-313. [CrossRef]

40. Huang, Y.; McColl, W.F. An improved simplex method for function minimization. In Proceedings of the 1996 IEEE International Conference on Systems, Man and Cybernetics. Information Intelligence and Systems (Cat. No. 96CH35929), Beijing, China, 14-17 October 1996; pp. 1702-1705.

41. Takahama, T.; Sakai, S. Constrained optimization by applying the $\alpha$ constrained method to the nonlinear simplex method with mutations. IEEE Trans. Evol. Comput. 2005, 9, 437-451. [CrossRef]

42. Wang, P.C.; Shoup, T.E. Parameter sensitivity study of the Nelder-Mead Simplex Method. Adv. Eng. Softw. 2011, 42, 529-533. [CrossRef]

(C) 2020 by the authors. Licensee MDPI, Basel, Switzerland. This article is an open access article distributed under the terms and conditions of the Creative Commons Attribution (CC BY) license (http://creativecommons.org/licenses/by/4.0/). 